\title{
Relative Abuse Liability of GHB in Humans: A Comparison of Psychomotor, Subjective, and Cognitive Effects of Supratherapeutic Doses of Triazolam, Pentobarbital, and GHB
}

\author{
Lawrence P Carter', Brian D Richards', Miriam Z Mintzer' and Roland R Griffiths*, 1,2 \\ 'Department of Psychiatry and Behavioral Sciences, Johns Hopkins University School of Medicine, Baltimore, MD, USA; ${ }^{2}$ Department \\ of Neuroscience, Johns Hopkins University School of Medicine, Baltimore, MD, USA
}

\begin{abstract}
Although preclinical studies suggest that GHB has low likelihood for abuse, case reports indicate that GHB is abused. This study evaluated the relative abuse liability of GHB in 14 volunteers with histories of drug abuse. Psychomotor, subjective, and cognitive effects of a broad range of GHB doses $(2-18 \mathrm{~g} / 70 \mathrm{~kg})$, up to a dose that produced severe behavioral impairment in each participant, were compared to placebo and two abused sedative/hypnotic drugs, triazolam (0.5 and I mg/70 kg) and pentobarbital (200 and $400 \mathrm{mg} / 70 \mathrm{~kg})$, under double-blind, double-dummy conditions at a residential research facility. In general, GHB produced effects similar to triazolam and pentobarbital, although GHB was not identified as a benzodiazepine or barbiturate by participants that correctly identified triazolam and pentobarbital as such. On most measures of likelihood of abuse (eg ratings of liking, reinforcing effects), effects of pentobarbital were significantly greater than those of triazolam, with GHB being intermediate. GHB produced significantly greater negative subjective effects, including nausea, than the other drugs. Memory impairment after GHB was less than that after triazolam and pentobarbital. Within participants, the dose-effect function for sedation was steeper for GHB than for triazolam and pentobarbital. Also, at higher doses, GHB was associated with greater sedation and more variability across participants in sedation. Taken together, these data suggest that the profile of effects of GHB only partially overlaps with that of triazolam and pentobarbital. Although the likelihood for GHB to be abused is intermediate to triazolam and pentobarbital, the possibility of accidental overdose (ie greater sedation than intended) with GHB appears to be greater.
\end{abstract}

Neuropsychopharmacology (2006) 3 I, 2537-255I. doi:I0.1038/sj.npp. I30 I |46; published online 26 July 2006

Keywords: GHB; triazolam; pentobarbital; drug abuse; subjective effects; human

\section{INTRODUCTION}

Gamma-hydroxybutyric acid (GHB) is a metabolite of the inhibitory neurotransmitter gamma-aminobutyric acid (GABA) that fulfills many of the criteria of a neurotransmitter (Maitre, 1997). GHB is used clinically for treatment of narcolepsy in the US (Xyrem; Fuller and Hornfeldt, 2003; Borgen et al, 2004) and for treatment of alcoholism in Europe (Alcover; Poldrugo and Addolorato, 1999; Beghè and Carpanini, 2000). Reports of GHB overdose (Caldicott et al, 2004; Kintz et al, 2005), withdrawal (Galloway et al, 1997), and drug-facilitated sexual assault (Schwartz et al, 2000; Varela et al, 2004) have appeared in the literature and are thought to be related to the recreational

\footnotetext{
*Correspondence: Dr RR Griffiths, Department of Psychiatry and Behavioral Sciences, Johns Hopkins University-BPRU, 55 I0 Nathan Shock Drive, Baltimore, MD 21224, USA, Tel: + I 410 550-0034, Fax: + I 410550 0030, E-mail: rgriff@jhmi.edu

Received 14 February 2006; revised 24 May 2006; accepted 30 May 2006

Online publication: 31 May 2006 at http://www.acnp.org/citations/ Npp053106060093/default.pdf
}

use of GHB, which has been reported in North America (Miotto et al, 2001; Romanelli et al, 2003; Barrett et al, 2005), Europe (Bellis et al, 2003; Gonzalez and Nutt, 2005; Liechti et al, 2006), and Australia (Degenhardt et al, 2005).

Despite these reports of recreational GHB use by humans, the results of preclinical studies of the reinforcing effects of GHB in rodents and non-human primates have been equivocal (for a review see Nicholson and Balster, 2001). For example, GHB was not self-administered intravenously (i.v.) in four monkeys trained to self-administer PCP (Beardsley et al, 1996), but was self-administered more than saline (but less than methohexital) by two out of three monkeys trained to self-administer methohexital (Woolverton et al, 1999). In studies that have reported i.v. selfadministration of GHB in mice, the total dose of GHB that was self-administered was either not reported (Martellotta et al, 1998) or was relatively low $(5-7 \mathrm{mg} / \mathrm{kg}$; Fattore et al, 2001 ) and there was no additional evidence to suggest that the doses of GHB that were self-administered ( 0.05 and $0.1 \mathrm{mg} / \mathrm{kg} / \mathrm{inf}$ ) were discriminable or had other behavioral effects. Rats have been shown to consume more of a GHB (sodium salt) solution than water in a two-bottle choice 
procedure (Colombo et al, 1995); however, in the same procedure, rats consumed the same amount of sodium chloride solution as GHB solution, and did so in a (salt) concentration-dependent manner (Colombo et al, 1998). Lastly, GHB (175-350 mg/kg) has been shown to produce conditioned place preference in rats; however, a greater number of conditioning trials was required with GHB than with other classes of drugs such as opioids and amphetamines, suggesting that GHB might not be as reinforcing as other drugs of abuse (Martellotta et al, 1997; Itzhak and Ali, 2002). Thus, results of the evaluation of the relative reinforcing effects of $\mathrm{GHB}$ in rodents and non-human primates have been somewhat inconsistent, which might be partly due to the use of different species, routes of administration, doses, and behavioral end points.

Few clinical studies have evaluated abuse-related effects of $\mathrm{GHB}$, and to our knowledge, no study has specifically examined the abuse liability of supratherapeutic doses of $\mathrm{GHB}$ in a population of recreational sedative abusers. In one study in opioid-dependent patients, $30 \mathrm{mg} / \mathrm{kg}(2.1 \mathrm{~g} / 70 \mathrm{~kg})$ GHB was found to significantly increase subjective ratings of 'good mood,' 'spaced,' 'sluggish,' and 'carefree' without significantly affecting psychomotor performance or ratings of 'liking' (Rosen et al, 1997). In an unblinded outpatient study that evaluated the ability of a larger dose of GHB ( $50 \mathrm{mg} / \mathrm{kg}$ or $3.5 \mathrm{~g} / 70 \mathrm{~kg}$ tid) given three times daily for 24 weeks to promote abstinence from alcohol in alcoholdependent patients, approximately $10 \%$ of the patients increased the dose of GHB by 6-7 times the therapeutic dose to $300-350 \mathrm{mg} / \mathrm{kg}$ tid (21-24.5 g/70 kg tid), suggesting that GHB was reinforcing in this subset of alcoholic patients (Addolorato et al, 1996).

The present placebo-controlled, double-blind study was undertaken to evaluate the relative abuse liability and to compare the psychomotor, subjective, and cognitive effects of GHB to triazolam and pentobarbital in participants with histories of sedative drug abuse. Triazolam and pentobarbital were chosen as positive controls because these compounds are known to be abused (Griffiths and Johnson, 2005), have well-characterized positive reinforcing effects in humans (Roache and Griffiths, 1985; Zawertailo et al, 2003), are used for therapeutic indications similar to GHB (ie induction of sleep and alcohol withdrawal), and have mechanisms of action similar to GHB (ie GABAergic). A variety of psychomotor, subjective, and cognitive measures were assessed at different time points to characterize the time course and peak effects of triazolam, pentobarbital, and GHB at different doses. The experimental approach was similar to that used extensively to evaluate the relative abuse liability of sedative/hypnotics (Griffiths et al, 2003), with the exception that, due to the limited amount of information available for selecting specific GHB doses and the anticipated steep dose-effect function for GHB, the design of this study involved testing progressively increasing doses of GHB.

\section{MATERIALS AND METHODS}

\section{Participants}

Participants were 12 adult male and two adult female subjects with histories of abuse of sedative/hypnotic drugs and without significant medical or psychiatric illness (other than substance abuse). One participant reported extensive past experience with GHB. Eleven participants were Caucasian (79\%) and three were African-American (21\%). The median age of participants was 27 years (range: $20-43$ ) and the median weight was $72 \mathrm{~kg}$ (range: 60-98). Details regarding participant screening and informed consent are similar to those described previously (Griffiths et al, 1980). This study was approved by the Institutional Review Board of Johns Hopkins University School of Medicine. Participants gave their written informed consent before beginning the study and were paid for their participation.

\section{General Procedures}

After completing the screening procedures, eligible individuals were admitted to the residential behavioral pharmacology research unit at Johns Hopkins University Bayview Campus. Participants were informed that during their participation they would receive various drugs, administered orally, that could include sedatives, muscle relaxants, antianxiety medications, antihistamines, stimulants, and weight loss medications. They were also informed that one of the drugs they would receive would be $\mathrm{GHB}$, an FDA-approved sleep-inducing agent for the treatment of narcolepsy. The consent form also indicated that, 'small doses [of GHB] usually produce an effect similar to alcohol' and 'larger doses induce loss of consciousness and sleep.' Other than receiving this general information, participants were blind to the type of drug administered each day. Participants were told that the purpose of the study was to determine how different drugs affect mood and behavior. Other than this general explanation of purpose, participants were given no instruction of what they were supposed to do or of what outcomes might be expected, although they were required to practice the psychomotor and computer tasks (eg Circular Lights and Computer Questionnaires) before the start of the study. Before admission to the residential unit, participants provided a urine sample that was screened for the presence of commonly abused drugs.

On the first day of the study, participants received $300 \mathrm{mg} / 70 \mathrm{~kg}$ pentobarbital under single-blind conditions to determine whether they reported liking the effects of this dose of pentobarbital and for training and acclimation to the experimental procedures. This day also allowed for acclimation to the residential unit. Participants who reported liking pentobarbital on the Next Day Questionnaire (described below) were allowed to continue in the study. All participants reported liking $300 \mathrm{mg} / 70 \mathrm{~kg}$ pentobarbital. Experimental sessions were conducted 5 days per week (Monday to Friday), and participants followed a daily routine.

Participants were awoken by 0700 hours and were allowed to smoke cigarettes until approximately 0800 hours. Participants were maintained on a caffeine-free diet for the duration of the study and were not allowed to eat or drink caloric beverages from 0000 hours (ie midnight) the night before a session. Participants were allowed to smoke cigarettes and eat after 1200 hours (ie noon) or after the drug effect dissipated, whichever occurred later. There did 
not appear to be any signs of acute withdrawal (eg from nicotine or caffeine) over the course of this study.

The test room contained a hospital bed, two chairs, a desk, an Apple Macintosh computer (Apple Computer, Inc., Cupertino, CA), and an automated ECG and blood pressure monitor (Criticare Systems Inc., Waukesha, WI). A crash cart was available in case of a medical emergency. When not actively completing an experimental task, participants were allowed to engage in recreational activities (eg watching television or reading).

During the study participants could receive a maximum of 13 different treatment conditions over 13 experimental sessions (placebo; 0.5 and $1.0 \mathrm{mg} / 70 \mathrm{~kg}$ triazolam; 200 and $400 \mathrm{mg} / 70 \mathrm{~kg}$ pentobarbital; and $2,4,8,10,12,14,16$, and $18 \mathrm{~g} / 70 \mathrm{~kg} \mathrm{GHB})$. The order of the four drug and placebo conditions (triazolam, pentobarbital, GHB, and placebo) was counterbalanced across participants. Within each type of drug condition the sequence of the doses was always ascending, and dosing within each type of condition was completed before proceeding to another type (eg both doses of triazolam were administered before proceeding to pentobarbital). The ascending sequence was used to determine the maximum dose of GHB that could be safely tolerated by individual participants and to avoid adverse events that might result if an individual was particularly sensitive to GHB. For each participant, the highest dose of GHB tested was one that produced severe functional impairment (ie the participant could not complete the subjective tasks and also had scores of 0 on the psychomotor tasks at the same time point; for scoring procedures, see Psychomotor performance measures below).

When the highest dose of GHB had been determined, higher doses of $\mathrm{GHB}$ were removed from the dosing sequence and the remaining treatment conditions were administered in the previously determined order. For three individuals, a dose of $6 \mathrm{~g} / 70 \mathrm{~kg}$ GHB was inserted into the dose order between 4 and $8 \mathrm{~g} / 70 \mathrm{~kg}$ because data from earlier participants suggested that the GHB dose-effect curve was steep and that the effects of $8 \mathrm{~g} / 70 \mathrm{~kg}$ GHB were substantially stronger than those of $4 \mathrm{~g} / 70 \mathrm{~kg}$ GHB. For one of the three participants who received $6 \mathrm{~g} / 70 \mathrm{~kg} \mathrm{GHB}$, this dose was also the highest dose tested (ie this person did not receive $8 \mathrm{~g} / 70 \mathrm{~kg} \mathrm{GHB}$ ).

On experimental days, lactose (placebo), triazolam, or pentobarbital was administered in capsules and sodium citrate (GHB placebo) or $\mathrm{GHB}$ was administered as a solution under double-blind, double-dummy conditions. Drug or placebo administration occurred at approximately 0845 hours and psychomotor performance tasks, subjective measures, and the Digit Enter and Recall task were completed before administration (approximately 08000830 hours) and at $0.5,1,2,3,4,6,8,12$, and $24 \mathrm{~h}$ after administration. For safety monitoring, heart rate and blood pressure were assessed at these same time points and at 15 min intervals within the first 90 min after administration. On the last experimental day of the study (ie the lottery day'), participants received the consequence that was randomly selected from all of the choices that the participant made in the drug vs money Multiple Choice Procedure (described below) and experimental procedures were conducted as usual.

\section{Drugs}

Lactose monohydrate (placebo; Amend Drug and Chemical Company, Irvington, NJ), triazolam (Upjohn Co., Kalamazoo, MI), and pentobarbital (Abbott Labs, Abbott Park, IL) were orally administered in capsules. GHB $(500 \mathrm{mg} / \mathrm{ml}$ sodium oxybate solution) and GHB placebo (an equimolar sodium citrate $(389 \mathrm{mg} / \mathrm{ml})$ solution matched for $\mathrm{pH}$ ) were orally administered as solutions (Orphan Medical; Minnetonka, MN, now known as Jazz Pharmaceuticals, Palo Alto, CA). The dose of GHB was adjusted by varying the volume of sodium oxybate in the administered solutions; however, the combined volume of sodium oxybate and sodium citrate was always $40 \mathrm{ml}$ to keep the sodium concentration constant. The total volume of the GHB and GHB placebo solutions that were administered was $400 \mathrm{ml}$ and was prepared by diluting $40 \mathrm{ml}$ of sodium oxybate and placebo or placebo alone with distilled/ deionized water and fruit juice.

\section{Psychomotor Performance Measures}

Balance. This task began with the participant raising one foot off of the floor with his or her eyes closed. The time that a participant remained on one foot without opening his or her eyes or touching the floor or another part of his or her body with the raised foot was measured up to $30 \mathrm{~s}$. Balance was measured for each foot and summed across both feet. If a participant could not perform the task, a score of $0 \mathrm{~s}$ was recorded.

Circular Lights. The dependent measure for this previously described button pressing task (Griffiths et al, 1983) was the number of correct presses (ie lights extinguished) in $60 \mathrm{~s}$. If a participant could not perform the task, a score of 0 was recorded.

Digit-symbol-substitution task (DSST). This task was a computer version (McLeod et al, 1982) of the digit-symbolsubstitution task (Wechsler, 1958). The dependent measure was the number of correct patterns that was reproduced within $90 \mathrm{~s}$. If a participant could not perform the task, a score of 0 was recorded.

\section{Participant- and Observer-Rated Measures}

Unless otherwise stated, all questionnaires were administered on an Apple Macintosh computer. The participants and staff used a computer mouse to point and select response options displayed on the computer monitor.

Observer-rated measures. A previously described Observer-Rated Questionnaire consisted of eight items rated on a five-point scale (Rush et al, 1999). Staff also rated participants' level of alertness on a five-point scale consisting of the following five options: '5- awake and alert,' ' $4-$ drowsy, but easily aroused with verbal commands,' '3-drowsy or asleep, responding to verbal and light tactile stimulation,' '2-drowsy or asleep, not responding to loud voice, responding to rougher tactile stimulation only,' ' 1 - asleep, responding to pain only.' In general, tactile stimulation consisted of touching or gently 
shaking a drowsy or sleeping participant whereas nociceptive stimuli consisted of pressure applied to the nail bed of a finger or toe, or a sternal rub.

Drug Effect Questionnaire. This previously described questionnaire (Mumford et al, 1995), consisted of a fivepoint drug strength rating and a nine-point drug likingdisliking rating. For purposes of data analysis, ratings of drug liking were assigned a score of 0 if participants indicated disliking (Mumford et al, 1995).

Subjective Effects Questionnaire. This previously described questionnaire (Rush et al, 1999) consisted of ratings of sleepiness on a visual analog scale and ratings of 34 somatic and other subjective effects on a five-point scale.

Next Day Questionnaire. This previously described questionnaire (Rush et al, 1999), which was completed approximately $24 \mathrm{~h}$ after drug administration, consisted of five items rated on a five-point scale and two items answered with a numerical value in dollars and cents.

Drug vs money Multiple Choice Procedure. This procedure, which has been previously described in detail (Griffiths et al, 1993; Mintzer and Griffiths, 1998) involves an assessment of the participants' preference to receive the previously administered solution and capsules (a dose of drug or placebo) or an amount of money. Approximately, $24 \mathrm{~h}$ after drug administration, participants completed a series of 65 questions asking whether they would prefer to receive, 'yesterday's drug' or an amount of money. Positive and negative monetary values $(-\$ 40.00$ to $\$ 40.00)$ were included such that participants could gain (ie receive money instead of drug) or lose (ie pay to avoid the drug) money based on their preference for the drug. On the last session of the study (ie the lottery day), one of the choices from this procedure was randomly reinforced; the dose of drug or placebo was administered and the amount of money was credited to, or debited from, the participant's account. The dose of drug or placebo was administered and the session was conducted as usual. The dependent measure was the highest monetary value at which drug was chosen over money (ie the crossover point). Negative crossover points were analyzed as zeros to reduce the variability from participants that would pay varying amounts of money to avoid a drug.

Pharmacological Class Questionnaire. This previously described questionnaire (Rush et al, 1999), which was completed approximately $24 \mathrm{~h}$ after drug administration, listed descriptive titles and examples of 12 classes of psychoactive drugs, 'blank or placebo,' and 'other.' Participants were instructed to choose the option that they believed most closely represented the compound that they had received the previous day. Additionally, participants completed a brief written description of the drug effects.

\section{Cognitive Performance Measures}

Digit Enter and Recall. This task was a version of the number recall task that has been adapted for use on Apple
Macintosh computers (Roache and Griffiths, 1987). In the first component of the task (enter), participants were instructed to reproduce the number using the keyboard while the number remained on the monitor. In the second component of the task (recall), the participants were instructed to reproduce the number after $0 \mathrm{~s}$ (five trials) or $10 \mathrm{~s}$ (five trials) after the number disappeared from the monitor. The session ended after 10 eight-digit numbers were correctly reproduced in the first component (ie 10 trials were initiated) or after the incorrect entry of 25 eight-digit numbers. The dependent measures were the percentage of eight-digit numbers that were correctly reproduced and the percentage of those numbers that were correctly recalled.

Word Recognition and Recall. For these tasks, 16 words were presented sequentially on a computer monitor $1 \mathrm{~h}$ after drug administration and participants were informed that their memory for these words would be evaluated at a later time. Participants were required to rate the pleasantness of each word on a scale of 1 (least pleasant) to 7 (most pleasant) to encourage them to read and think about the words that were presented. At $5 \mathrm{~h}$ after the presentation of the words (6 $\mathrm{h}$ after drug administration), the Word Recall component commenced in which participants were asked to recall as many words as they could remember from the words that were presented that morning. The dependent measure was the number of correct words recalled (written down) within $5 \mathrm{~min}$. The Word Recognition task followed the Word Recall task and consisted of the randomly sequenced presentation of the 16 old words that had been presented earlier and 16 new words that were not previously presented to the participant. Participants were instructed to respond by selecting a button on the monitor labeled, 'old' if they recognized the word from the earlier presentation of the words and to select on a button labeled, 'new' if they did not recognize the word from the prior presentation. The dependent measure for the Word Recognition task was d', an index of the participant's ability to discriminate new and old words, which is calculated from the number of old words identified as old and the number of new words identified as old (Snodgrass and Corwin, 1988).

\section{Data Analyses}

For the Drug Effect Questionnaire, Subjective Effects Questionnaire, and Observer-Rated Questionnaire, peak effect for each participant was defined as the maximum value from 0.5 to $12 \mathrm{~h}$ after drug administration. For the Balance, Circular Lights, Digit Enter and Recall, DSST, and observer ratings of level of alertness, peak effect for each participant was defined as the minimum value from 0.5 to $12 \mathrm{~h}$ after drug administration. The General Linear Model (GLM) was used for all analysis of variance (ANOVA) calculations; all statistical tests were performed using SPSS (SPSS Inc., Chicago, IL) and $p<0.05$ was considered significant.

Two sets of analyses were conducted, dose-effect analyses and time course analyses. Dose-effect analyses used one factor repeated measures ANOVA with condition (placebo, 0.5 and $1 \mathrm{mg} / 70 \mathrm{~kg}$ triazolam, 200 and $400 \mathrm{mg} / 70 \mathrm{~kg}$ pentobarbital, and three doses of GHB) as the factor (see 
below). Planned comparisons ( $t$-tests) between placebo and the seven active drug conditions, and between selected doses of drugs, were conducted using the error variance for the two means being compared; to minimize the chance of Type I error, these results are reported only when the $\mathrm{F}$ statistic of the ANOVA was significant. Data analyzed were peak psychomotor performance measures, peak ratings from the Observer-Rated Questionnaire, Drug Effect Questionnaire, and Subjective Effects Questionnaire, ratings from the Next Day Questionnaire, crossover point from the Multiple Choice Procedure, peak effects from the Digit Enter and Recall task, and the number of words and d' values from the Word Recall and Word Recognition tasks, respectively.

For the dose-effect analyses, because different participants were exposed to different doses of GHB, statistical analyses were performed three different ways: (1) using 2, 4, and $8 \mathrm{~g} / 70 \mathrm{~kg} \mathrm{GHB}$ in the 13 participants who received those doses $(N=13)$; (2) using 2 , 4 , and 6 or $8 \mathrm{~g} / 70 \mathrm{~kg}$ GHB $(N=14)$ by combining the data for the one participant that received a maximum dose of $6 \mathrm{~g} / 70 \mathrm{~kg}$ with those that received $8 \mathrm{~g} / 70 \mathrm{~kg}$; and (3) using $2,4 \mathrm{~g} / 70 \mathrm{~kg}$, and the highest dose of GHB that each participant received $(N=14)$, which was $6 \mathrm{~g} / 70 \mathrm{~kg}$ for one participant, $8 \mathrm{~g} / 70 \mathrm{~kg}$ for nine participants, $10 \mathrm{~g} / 70 \mathrm{~kg}$ for two participants, $12 \mathrm{~g} /$ $70 \mathrm{~kg}$ for one participant, and $18 \mathrm{~g} / 70 \mathrm{~kg}$ for one participant. In general, the qualitative and quantitative results of analysis 1 using only participants that received $8 \mathrm{~g} / 70 \mathrm{~kg}$ GHB $(N=13)$ was very similar to analysis 2 that combined the data for the one participant that received a maximum dose of $6 \mathrm{~g} / 70 \mathrm{~kg}$ with those that received $8 \mathrm{~g} / 70 \mathrm{~kg}$; therefore, only data from analyses 1 and 3 are presented and discussed here.

Time course analyses examined the effects of measures assessed repeatedly after drug administration. These analyses used two-factor repeated measures ANOVA with condition (placebo, 0.5 and $1 \mathrm{mg} / 70 \mathrm{~kg}$ triazolam, 200 and $400 \mathrm{mg} / \mathrm{kg}$ pentobarbital, and 2, 4 , and $8 \mathrm{~g} / 70 \mathrm{~kg} \mathrm{GHB}$ ) and time $(0.5,1,2,3,4,6,8$, and $12 \mathrm{~h}$ after drug) as factors $(N=13)$. Planned comparisons ( $t$-tests) of placebo with each of the drug conditions at each postdrug time point were conducted using the error variance for the two means being compared; to minimize the chance of Type I error, these results are reported only when the F statistic of the ANOVA was significant.

On the Pharmacological Class Questionnaire, correct identification of triazolam and pentobarbital dose conditions as benzodiazepine or barbiturate varied among participants, possibly reflecting different histories with these compounds. Therefore, data from the Pharmacological Class Questionnaire are presented only for participants that (correctly) identified three out of the four doses of triazolam and pentobarbital as either a benzodiazepine or a barbiturate $(N=6)$ and were not analyzed statistically.

\section{RESULTS}

\section{Ascending Dose Sequences and Level Of Sedation}

In this ascending dose sequence design, all participants received placebo and doses of 0.5 and $1.0 \mathrm{mg} / 70 \mathrm{~kg}$ triazolam, 200 and $400 \mathrm{mg} / 70 \mathrm{~kg}$ pentobarbital, and 2 and $4 \mathrm{~g} / 70 \mathrm{~kg}$ GHB. Each participant also received one or more higher doses of GHB, up to a dose that produced severe functional impairment (ie the participant could not complete the subjective tasks and also had scores of 0 on the psychomotor tasks at the same time point). The highest dose of GHB that was received varied markedly across the participants $(6 \mathrm{~g} / 70 \mathrm{~kg}, N=1 ; 8 \mathrm{~g} / 70 \mathrm{~kg}, N=9 ; 10 \mathrm{~g} / 70 \mathrm{~kg}$, $N=2 ; 12 \mathrm{~g} / 70 \mathrm{~kg}, N=1$; and $18 \mathrm{~g} / 70 \mathrm{~kg}, N=1)$.

On the observer-rated level of alertness scale, all three drugs produced dose-related increases in sedation as reflected in the peak minimum level of alertness ratings (Table 1). Both doses of triazolam and pentobarbital produced ratings of drowsy or asleep on the level of alertness scale. In contrast, the majority of participants remained awake and alert after administration of 2 or $4 \mathrm{~g} / 70 \mathrm{~kg}$ GHB . The larger dose of $8 \mathrm{~g} / 70 \mathrm{~kg} \mathrm{GHB}$, like $1 \mathrm{mg} /$ $70 \mathrm{~kg}$ triazolam and $400 \mathrm{mg} / 70 \mathrm{~kg}$ pentobarbital, produced some level of sedation in almost all ( $>90 \%)$ participants; however, unlike $1 \mathrm{mg} / 70 \mathrm{~kg}$ triazolam and $400 \mathrm{mg} / 70 \mathrm{~kg}$ pentobarbital, $8 \mathrm{~g} / 70 \mathrm{~kg}$ GHB produced a greater level of sedation in some participants (Table 1). In almost one-third of the participants that received $8 \mathrm{~g} / 70 \mathrm{~kg}$ GHB $(31 \%)$, nociceptive (ie painful) stimuli were required to elicit a response from the participant, whereas nociceptive stimuli

Table I Peak Minimum Observer-Rated Level of Alertness ${ }^{\mathrm{a}}$

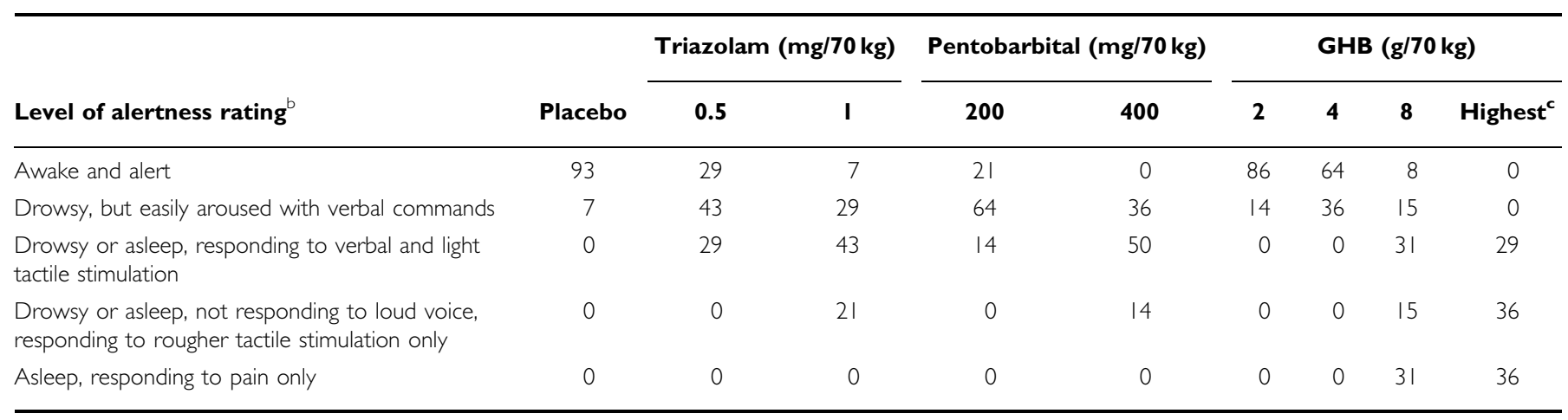

${ }^{a}$ Data show the percentage of participants that were assessed as reaching the indicated level of alertness rating in each dose condition $(\mathrm{N}=14$ for each condition except $8 \mathrm{~g} / 70 \mathrm{~kg} \mathrm{GHB}, \mathrm{N}=13)$.

${ }^{b}$ Peak minimum rating of level of alertness for the $3 \mathrm{~h}$ period after drug administration.

'Highest dose of GHB that each individual participant received. 
were never required after administration of $1 \mathrm{mg} / 70 \mathrm{~kg}$ triazolam or $400 \mathrm{mg} / 70 \mathrm{~kg}$ pentobarbital. After the highest dose of GHB that was administered, all participants exhibited substantial sedation and more than two-thirds (10 out of 14 or $71 \%$ ) required rough tactile, or nociceptive, stimuli for arousal. Despite the marked sedation that was observed after large doses of GHB, respiration and blood pressure were well maintained and recovery from a strong GHB drug effect was generally rapid with participants often reporting feeling alert and well rested upon awakening.

\section{Time Course of Drug Effects}

Triazolam, pentobarbital, and GHB exhibited dose- and time-related behavioral, observer-rated, and participantrated effects. Figure 1 shows the time course of triazolam, pentobarbital, and GHB on three measures (Circular Lights, DSST, and Observer-ratings of drug strength) that are representative of the general time course of these drugs across each of the procedures used in this study. Each drug significantly decreased performance on the Circular Lights and DSST tasks and increased Observer-rated measures of drug strength (Figure 1). In general, maximal drug effects occurred $1-2 \mathrm{~h}$ after administration of each drug, although significant drug effects were observed as early as $30 \mathrm{~min}$ after administration of pentobarbital and larger doses of GHB (eg Figure 1, observer-rated drug strength). The duration of action of pentobarbital tended to be longer than that of triazolam and $\mathrm{GHB}$; for example, the effects of triazolam and GHB typically did not last more than 3-4h whereas a dose of pentobarbital (ie $400 \mathrm{mg} / 70 \mathrm{~kg}$ ) that produced effects similar to those of $1 \mathrm{mg} / 70 \mathrm{~kg}$ triazolam and $8 \mathrm{~g} / 70 \mathrm{~kg}$ GHB had significant behavioral and subjective effects up to $6-8 \mathrm{~h}$ after administration (eg Figure 1, DSST and Observer-rated drug strength). The highest doses of triazolam and pentobarbital significantly increased heart rate (by $12.5 \pm 2.5$, and $9.9 \pm 3.3$ beats per min (b.p.m.), respectively, $1 \mathrm{~h}$ after administration), which was maximal at $1 \mathrm{~h}$ (data not shown). The dose of $8 \mathrm{~g} / 70 \mathrm{~kg} \mathrm{GHB}$ significantly decreased heart rate (by $14.9 \pm 2.9$ b.p.m. at $2 \mathrm{~h}$ ), which was maximal at $2 \mathrm{~h}$. There were no marked effects on systolic or diastolic blood pressure following any of the drugs (data not shown).

\section{Psychomotor Performance and Observer-Rated Measures}

Triazolam, pentobarbital, and GHB significantly decreased participants' psychomotor performance and observer-rated level of alertness and increased observer-rated muscle relaxation, abnormal posture, and drug strength relative to placebo (Table 2). In general, the peak effects of $1 \mathrm{mg} /$ $70 \mathrm{~kg}$ triazolam, $400 \mathrm{mg} / 70 \mathrm{~kg}$ pentobarbital, and $8 \mathrm{~g} / 70 \mathrm{~kg}$ GHB on psychomotor performance and observer-rated measures were not markedly different from each other (Table 2; Figure 2). The highest dose of GHB that was administered to each participant was, by design, a dose that produced behavioral impairment. The rightmost
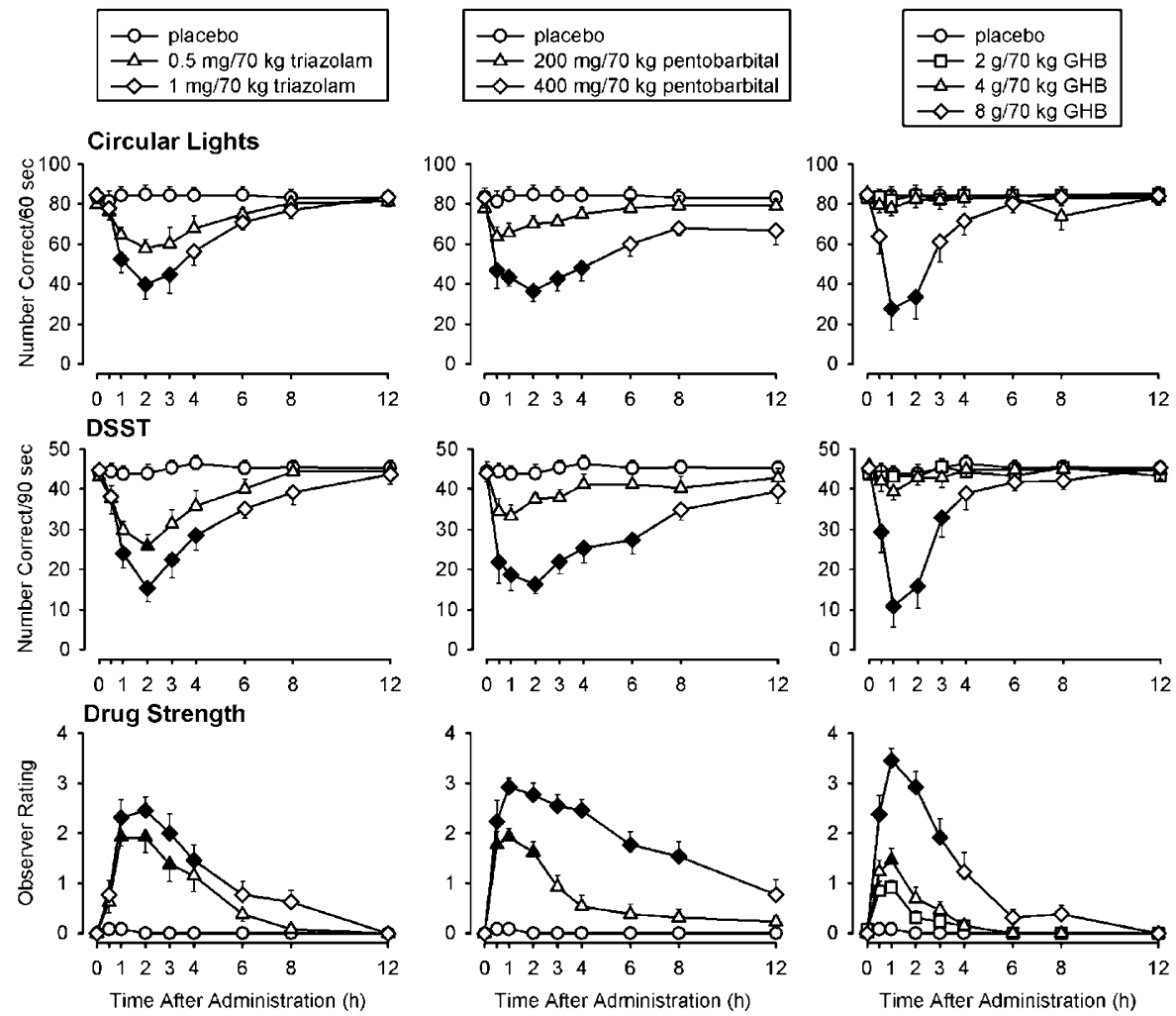

Figure I Time course of effects of triazolam (left panels), pentobarbital (center panels), and GHB (right panels) on circular lights, DSST, and observerrated drug strength. $Y$ axes: correct responses (Circular Lights and DSST) and ratings (observer-rated drug strength). $X$ axes: time after drug administration in hours ( 0 indicates predrug). Data points show means $(N=13)$; brackets show + or - I SEM. Filled symbols indicate values that are significantly different from the corresponding placebo value at the same time point ( $p<0.05$, planned comparisons). 
column in Table 2 indicates that the highest dose of GHB administered to each participant resulted in significantly lower psychomotor performance and level of alertness, and greater observer ratings of drug strength compared to the highest dose of pentobarbital $(400 \mathrm{mg} / 70 \mathrm{~kg})$ that was administered.

\section{Participant-Rated Measures}

Same-day participant-rated measures. As shown in the top panel of Figure 3, triazolam, pentobarbital, and GHB produced dose-related increases in participants' same-day ratings of drug effect. Similar dose-related increases were

Table 2 Summary of Significant Drug Effects and Comparisons between Selected Doses on Measures that could be Assessed at all Scheduled Time Points (ie, Assessment was not Precluded by Nonresponding at High GHB Doses)

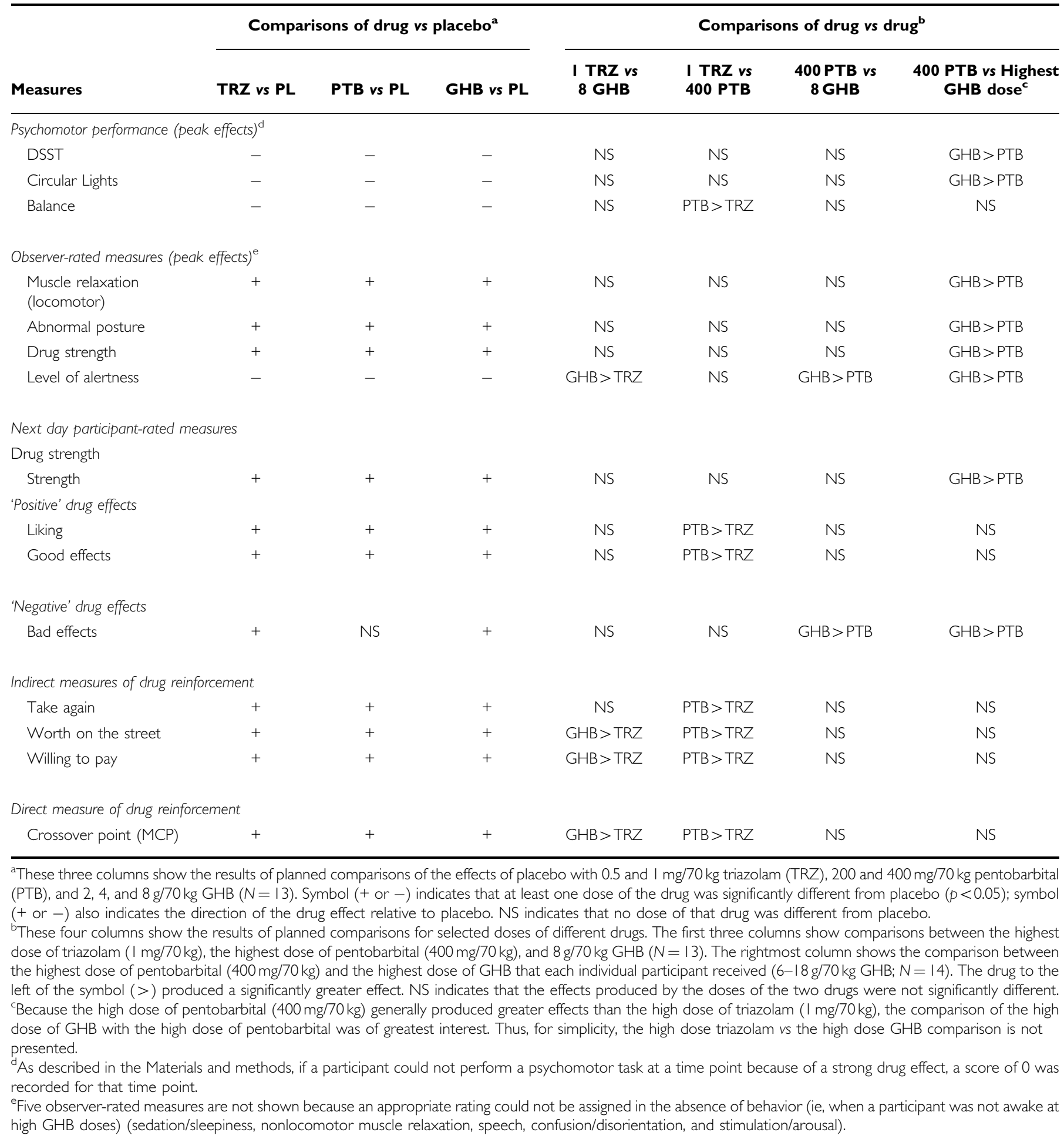


sychomotor Performance
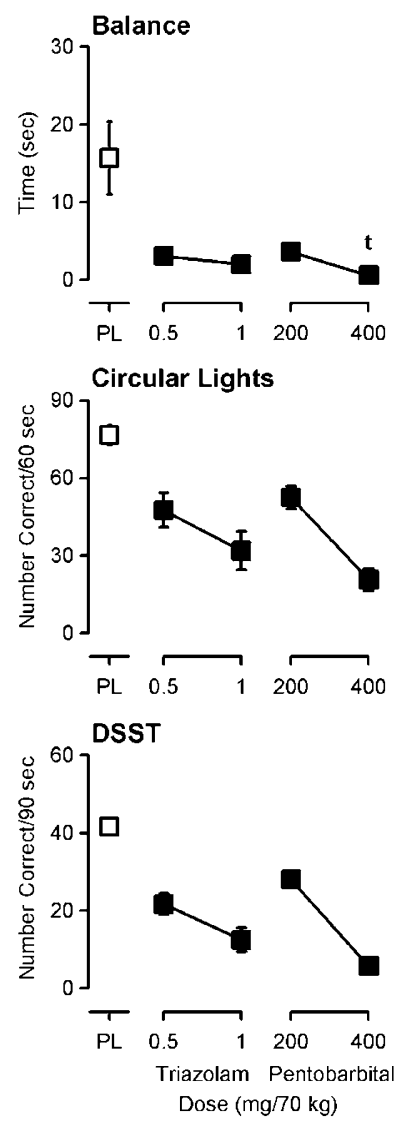
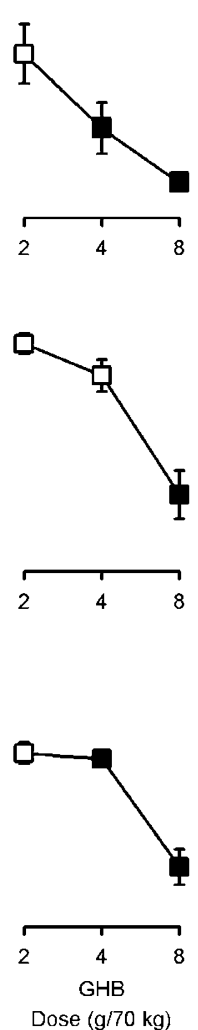
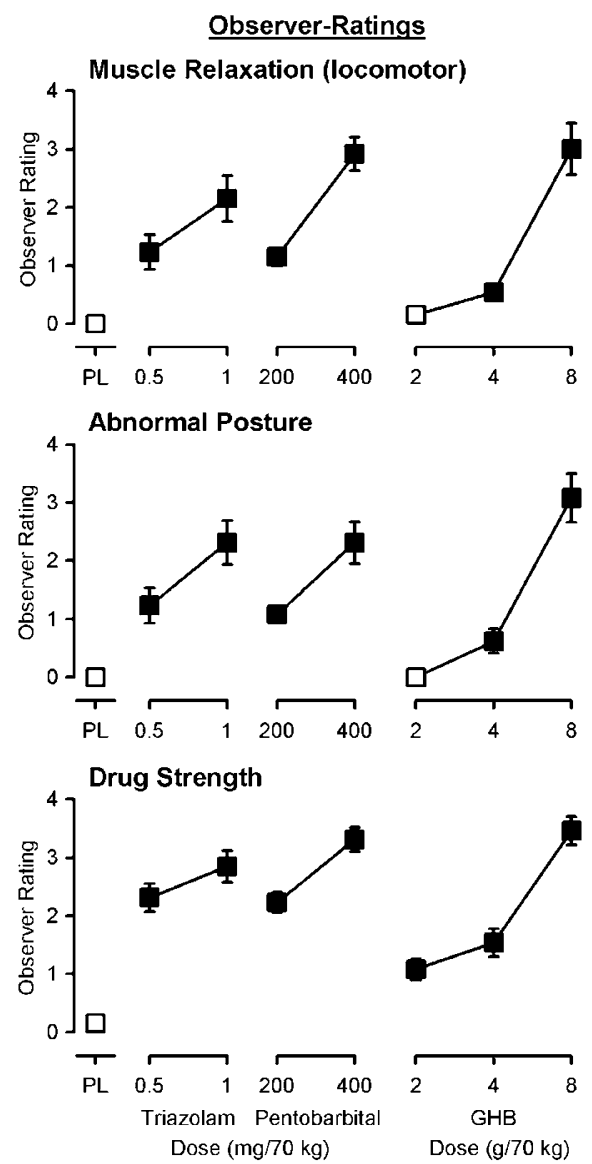

Figure 2 Psychomotor performance and observer-rated effects of triazolam, pentobarbital, and GHB. Y axes: score or rating expressed as peak effect; peak effects for psychomotor performance measures are the minimum values and peak effects for the observer-rated measures are the maximum values across the $12 \mathrm{~h}$ session. $X$ axes: dose in $\mathrm{mg}$ (triazolam and pentobarbital) or g (GHB) per $70 \mathrm{~kg}$ (log scale); PL designates placebo. Data points show means $(N=13)$; brackets show \pm I SEM and the absence of brackets indicates that I SEM fell within the area of the data symbol. Filled symbols indicate values that are significantly different from placebo; letters above $1 \mathrm{mg} / 70 \mathrm{~kg}$ triazolam, $400 \mathrm{mg} / 70 \mathrm{~kg}$ pentobarbital, and $8 \mathrm{~g} / 70 \mathrm{~kg}$ GHB indicate that these values are significantly different from the dose of drug designated by the letter ( $\mathrm{t}, \mathrm{p}$, and $\mathrm{g}$ for I mg/70 kg triazolam, $400 \mathrm{mg} / 70 \mathrm{~kg}$ pentobarbital, and $8 \mathrm{~g} / 70 \mathrm{~kg} \mathrm{GHB}$, respectively; $p<0.05$; planned comparisons)

shown on most same-day participant ratings of somatic and positive subjective effects. Table 3 summarizes the differences in peak subjective effects for all of the same-day participant-rated measures. It should be noted that these measures could not be assessed at all time points because of nonresponding (ie marked sedation), which occurred most often after $8 \mathrm{~g} / 70 \mathrm{~kg} \mathrm{GHB}$ and the highest dose of GHB that participants received. For subjective effects that were significantly increased relative to placebo, triazolam, pentobarbital, and GHB exhibited similar profiles across subjective effects, although GHB, unlike triazolam and pentobarbital, did not significantly increase ratings of slurred speech, forgetful, comfortable, or relaxed, at any dose (Table 3). Comparing the magnitude of subjective effects across drugs, in general, participants' same-day ratings of subjective effects after $400 \mathrm{mg} / 70 \mathrm{~kg}$ pentobarbital were significantly greater than those after $1 \mathrm{mg} / 70 \mathrm{~kg}$ triazolam or the highest dose of GHB (Table 3), despite similar or greater effects of the highest dose of GHB compared to $400 \mathrm{mg} / 70 \mathrm{~kg}$ pentobarbital on psychomotor performance and observer ratings of sedation and drug strength (cf., Table 2).
With regard to likelihood of abuse, triazolam, pentobarbital, and GHB significantly increased same-day measures of positive drug effects (eg liking and good effects) relative to placebo. In general, the magnitude of peak same-day participant ratings of positive drug effects did not differ between triazolam, pentobarbital, and GHB, although, $400 \mathrm{mg} / 70 \mathrm{~kg}$ pentobarbital was rated as having significantly greater good effects than $1 \mathrm{mg} / 70 \mathrm{~kg}$ triazolam and $8 \mathrm{~g} / 70 \mathrm{~kg}$ GHB (Table 3). Further, each of the measures of liking, like, and good effects were rated significantly greater after $400 \mathrm{mg} / 70 \mathrm{~kg}$ pentobarbital than after the highest dose of GHB that each participant received (Table 3, right column).

These apparent differences shown in Table 3 in liking between the $8 \mathrm{~g} / 70 \mathrm{~kg}$ dose of GHB relative to pentobarbital $v s$ the highest dose of GHB that each participant received relative to pentobarbital might have been a result of greater 'negative' drug effects associated with higher doses of GHB (Figure 3, bottom panels; Table 3). GHB was the only compound that significantly increased same-day participant ratings of queasy or sick to stomach and headache (Figure 3). Same-day ratings of queasy or sick to stomach were significantly greater after $8 \mathrm{~g} / 70 \mathrm{~kg}$ GHB 

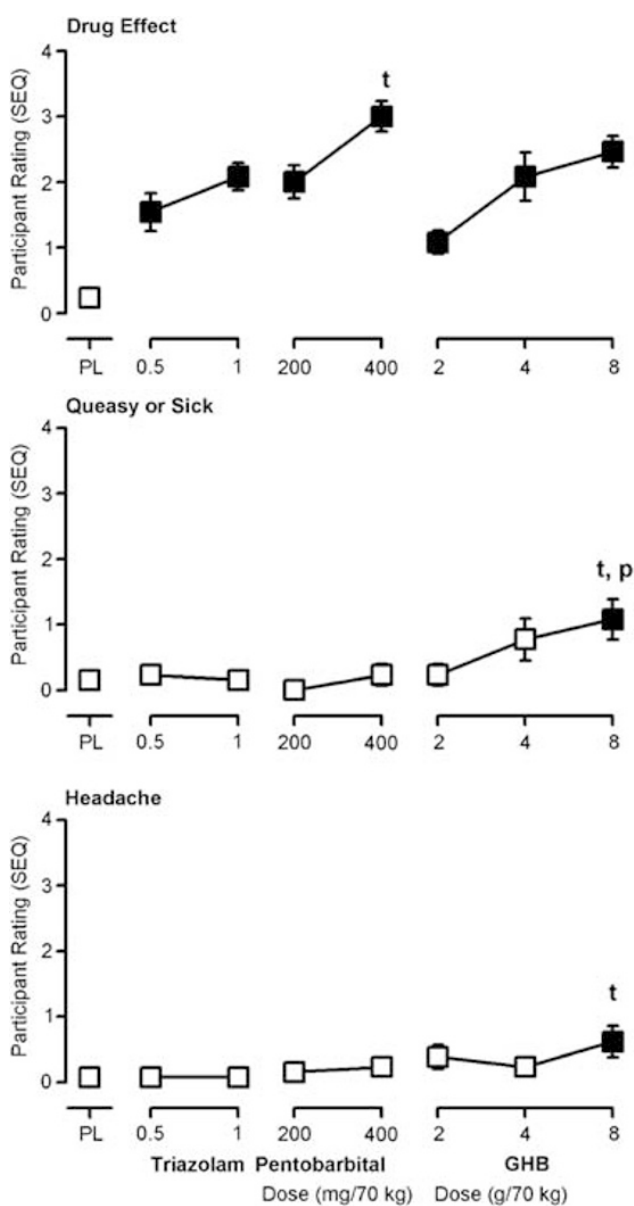

Figure 3 Ratings of same-day drug effect, queasy or sick to stomach, and headache for triazolam, pentobarbital, and GHB. Y axes: peak same-day ratings (Subjective Effects Questionnaire); peak effects are the maximum values across the $12 \mathrm{~h}$ session. $X$ axes: dose in $\mathrm{mg}$ (triazolam and pentobarbital) or g (GHB) per $70 \mathrm{~kg}$ (log scale); PL designates placebo. Data points show means $(N=13)$; brackets show \pm I SEM. See Figure 2 for other details.

and after the highest dose of GHB that each participant received compared to $400 \mathrm{mg} / 70 \mathrm{~kg}$ pentobarbital (Figure 3; Table 3).

Next-day participant-rated measures. On next-day ratings of drug strength, all three drugs produced similar doserelated increases (Figure 4, top left panel; Table 2). All three drugs significantly increased next-day participant ratings of positive subjective effects (liking and good effects), indirect measures of drug reinforcement (take again, worth on the street, and willing to pay), and a direct measure of drug reinforcement (crossover point from the Multiple Choice Procedure; Figure 4; Table 2). In general, the next-day indirect and direct measures of drug reinforcement after $400 \mathrm{mg} / 70 \mathrm{~kg}$ pentobarbital and $8 \mathrm{~g} / 70 \mathrm{~kg}$ GHB were greater than those after $1 \mathrm{mg} / 70 \mathrm{~kg}$ triazolam (Figure 4; Table 2). Specifically, next-day participant-rated measures after administration of $8 \mathrm{~g} / 70 \mathrm{~kg} \mathrm{GHB}$ were significantly greater than those after $1 \mathrm{mg} / 70 \mathrm{~kg}$ triazolam for worth, willing to pay, and the crossover point from the Multiple Choice Procedure (Figure 4, right panels), but not for take again, liking, and good effects (Figure 4, left panels). For all of these direct and indirect measures of reinforcement, the effects of $400 \mathrm{mg} / 70 \mathrm{~kg}$ pentobarbital were significantly greater than $1 \mathrm{mg} / 70 \mathrm{~kg}$ triazolam, but not significantly different from those of $8 \mathrm{~g} / 70 \mathrm{~kg}$ GHB or the highest dose of GHB that each participant received (Figure 4; Table 2, right column). The absence of differences in drug reinforcement between GHB and pentobarbital is notable given that the highest dose of GHB that was received produced significantly greater ratings of drug strength than the highest dose of pentobarbital (Table 2, right column).

Figure 4 (top right panel) also shows that all three doses of $\mathrm{GHB}$ and the highest dose of triazolam significantly increased next-day ratings of bad effects. Consistent with significant increases in same-day participant ratings of queasy or sick after GHB (Figure 3), open-ended comments on the Next Day Questionnaire indicated that nausea, gastrointestinal (GI) distress, diarrhea, or vomiting were common after doses of GHB (ie occurred after 41 and $78 \%$ of sessions in which $2-8$ and $10-18 \mathrm{~g} / 70 \mathrm{~kg}$ GHB were administered, respectively, compared with $4 \%$ and $14 \%$ of sessions in which triazolam and pentobarbital were administered, respectively). These negative effects were cited by participants as contributing to their disliking of GHB. In contrast, open-ended comments after triazolam uniformly cited memory loss as contributing to their disliking of the drug.

Pharmacological Class Questionnaire. Of the fourteen participants, six reliably identified doses of triazolam and pentobarbital as either a benzodiazepine or barbiturate on the next-day Pharmacological Class Questionnaire. In this subset of participants, five out of six $(83 \%)$ identified placebo as a blank or placebo, six out of six (100\%) identified 0.5 and $1 \mathrm{mg} / 70 \mathrm{~kg}$ triazolam as a benzodiazepine or barbiturate, and four out of six (67\%) identified 200 and $400 \mathrm{mg} / 70 \mathrm{~kg}$ pentobarbital as a benzodiazepine or barbiturate (data not shown). The dose of $2 \mathrm{~g} / 70 \mathrm{~kg}$ GHB was most commonly identified as a benzodiazepine or barbiturate with two out of six participants (33\%) selecting this class, whereas after $4 \mathrm{~g} / 70 \mathrm{~kg}$ GHB two out of six participants each chose blank or placebo, opiate, or other. The 'other' category was most commonly chosen after $8 \mathrm{~g} / 70 \mathrm{~kg}$ GHB (three out of six, 50\%), followed by opiate (two out of six, 33\%), and benzodiazepine or barbiturate (one out of six, $17 \%$; data not shown).

\section{Cognitive Performance Measures}

In general, the impairment of memory processes by GHB appeared to be less than what was observed following triazolam or pentobarbital (Figure 5). On a Digit Enter and Recall task, triazolam, pentobarbital, and GHB significantly decreased the peak percentage of eight-digit numbers that were correctly entered; however, only triazolam and pentobarbital significantly decreased the percentage of numbers that were recalled after each delay condition (Figure 5, top three panels). The peak effects of $8 \mathrm{~g} / 70 \mathrm{~kg}$ GHB were significantly less than $1 \mathrm{mg} / 70 \mathrm{~kg}$ triazolam and $400 \mathrm{mg} / 70 \mathrm{~kg}$ pentobarbital on the recall component, but not the enter component, suggesting that up to doses that produced comparable deficits in performance on the enter component, GHB did not significantly affect the 
Table 3 Summary of Significant Drug Effects and Comparisons between Selected Doses on Measures that could not be Assessed at all Scheduled Time Points Due to Nonresponding at High Drug Doses ${ }^{a, b}$

\begin{tabular}{|c|c|c|c|c|c|c|c|}
\hline \multirow[b]{2}{*}{ Measures } & \multicolumn{3}{|c|}{ Comparisons of drug vs placebo ${ }^{c}$} & \multicolumn{4}{|c|}{ Comparisons of drug vs drug ${ }^{d}$} \\
\hline & TRZ vs PL & PTB vs PL & GHB vs PL & $\begin{array}{l}\text { I TRZ vs } \\
8 \mathrm{GHB}\end{array}$ & $\begin{array}{l}\text { I TRZ vs } \\
400 \text { PTB }\end{array}$ & $\begin{array}{l}400 \text { PTB vs } \\
8 \text { GHB }\end{array}$ & $\begin{array}{l}400 \text { PTB vs Highest } \\
\text { GHB dose }\end{array}$ \\
\hline \multicolumn{8}{|c|}{ Same day participant-rated measures (peak effects) } \\
\hline \multicolumn{8}{|c|}{ Drug strength } \\
\hline Strength $(D E Q)^{f}$ & + & + & + & $\mathrm{GHB}>\mathrm{TRZ}$ & $\mathrm{PTB}>\mathrm{TRZ}$ & NS & $\mathrm{GHB}>\mathrm{PTB}$ \\
\hline \multicolumn{8}{|l|}{ Somatic and other subjective effects (SEQ) } \\
\hline Alert/sleepy VAS & + & + & + & NS & PTB $>$ TRZ & $\mathrm{PTB}>\mathrm{GHB}$ & $\mathrm{PTB}>\mathrm{GHB}$ \\
\hline Depressant or sedating & + & + & + & NS & PTB $>$ TRZ & $\mathrm{PTB}>\mathrm{GHB}$ & $\mathrm{PTB}>\mathrm{GHB}$ \\
\hline Confused or disoriented & + & + & + & NS & $\mathrm{PTB}>\mathrm{TRZ}$ & $\mathrm{PTB}>\mathrm{GHB}$ & $\mathrm{PTB}>\mathrm{GHB}$ \\
\hline Limp or loose & + & + & + & NS & NS & NS & NS \\
\hline Light-headed or dizzy & + & + & + & $\mathrm{GHB}>\mathrm{TRZ}$ & PTB $>$ TRZ & NS & NS \\
\hline Fatigued or weak & + & + & + & NS & NS & $\mathrm{PTB}>\mathrm{GHB}$ & NS \\
\hline Unsteady & + & + & + & $\mathrm{GHB}>\mathrm{TRZ}$ & $\mathrm{PTB}>\mathrm{TRZ}$ & $\mathrm{PTB}>\mathrm{GHB}$ & $\mathrm{PTB}>\mathrm{GHB}$ \\
\hline Difficulty concentrating & + & + & + & NS & $\mathrm{PTB}>\mathrm{TRZ}$ & $\mathrm{PTB}>\mathrm{GHB}$ & $\mathrm{PTB}>\mathrm{GHB}$ \\
\hline Slurred speech & + & + & NS & NS & NS & $\mathrm{PTB}>\mathrm{GHB}$ & $\mathrm{PTB}>\mathrm{GHB}$ \\
\hline Mentally slowed & + & + & + & NS & $\mathrm{PTB}>\mathrm{TRZ}$ & $\mathrm{PTB}>\mathrm{GHB}$ & $\mathrm{PTB}>\mathrm{GHB}$ \\
\hline Tired or lazy & + & + & + & NS & $\mathrm{PTB}>\mathrm{TRZ}$ & $\mathrm{PTB}>\mathrm{GHB}$ & $\mathrm{PTB}>\mathrm{GHB}$ \\
\hline Easy going or mellow & + & + & + & NS & NS & $\mathrm{PTB}>\mathrm{GHB}$ & $\mathrm{PTB}>\mathrm{GHB}$ \\
\hline Forgetful & + & + & NS & NS & NS & $\mathrm{PTB}>\mathrm{GHB}$ & $\mathrm{PTB}>\mathrm{GHB}$ \\
\hline \multicolumn{8}{|l|}{ 'Negative' drug effects } \\
\hline Headache (SEQ) & NS & NS & + & $\mathrm{GHB}>\mathrm{TRZ}$ & NS & NS & NS \\
\hline Queasy or sick to stomach (SEQ) & NS & NS & + & $\mathrm{GHB}>\mathrm{TRZ}$ & NS & $\mathrm{GHB}>\mathrm{PTB}$ & $\mathrm{GHB}>\mathrm{PTB}$ \\
\hline
\end{tabular}

${ }^{a}$ Missing data due to periods of nonresponding at high doses: ( 1 ) a total of 5 time points in four participants after I mg/70 kg triazolam; (2) a total of 5 time points in two participants after $400 \mathrm{mg} / 70 \mathrm{~kg}$ pentobarbital; (3) a total of 21 time points in eight participants after $8 \mathrm{~g} / 70 \mathrm{~kg} \mathrm{GHB}$; and (4) a total of 29 time points in eleven participants after the highest dose of GHB that each participant received.

${ }^{b}$ Eleven participant-rated measures are not shown because the F statistic was not significant (arousing or stimulant, hot or flushed, limbs heavy or rigid, talkative, excited, nervous or anxious, numbness or tingling, restless, energetic, shaky or jittery, and irritable or grumpy).

${ }^{\top}$ These three columns show the results of planned comparisons of placebo with 0.5 and I mg/70 kg triazolam (TRZ), 200 and $400 \mathrm{mg} / 70 \mathrm{~kg}$ pentobarbital (PTB), and 2, 4 , and $8 \mathrm{~g} / 70 \mathrm{~kg} \mathrm{GHB}(\mathrm{N}=13)$. Symbol (+ or -$)$ indicates that at least one dose of the drug was significantly different from placebo ( $p<0.05)$; symbol $(+$ or -$)$ also indicates the direction of the drug effect relative to placebo. NS indicates that no dose of that drug was different from placebo.

dThese four columns show the results of planned comparisons for selected doses of different drugs. The first three columns show comparisons between the highest dose of triazolam $(\mathrm{Img} / 70 \mathrm{~kg})$, the highest dose of pentobarbital $(400 \mathrm{mg} / 70 \mathrm{~kg})$, and $8 \mathrm{~g} / 70 \mathrm{~kg} \mathrm{GHB}(\mathrm{N}=13)$. The rightmost column shows the comparison between the highest dose of pentobarbital $(400 \mathrm{mg} / 70 \mathrm{~kg})$ and the highest dose of GHB that each individual participant received $(6-18 \mathrm{~g} / 70 \mathrm{~kg} \mathrm{GHB} ; \mathrm{N}=14)$. The drug to the left of the symbol $(>)$ produced a significantly greater effect. NS indicates that the effects produced by the doses of the two drugs were not significantly different. 'Because the high dose of pentobarbital $(400 \mathrm{mg} / 70 \mathrm{~kg}$ ) generally produced greater effects than the high dose of triazolam (I mg/70 kg), the comparison of the high dose of GHB with the high dose of pentobarbital was of greatest interest. Thus, for simplicity, the high dose triazolam vs the high dose GHB comparison is not presented.

fDEQ = Drug Effect Questionnaire.

${ }^{8} \mathrm{SEQ}=$ Subjective Effects Questionnaire. 

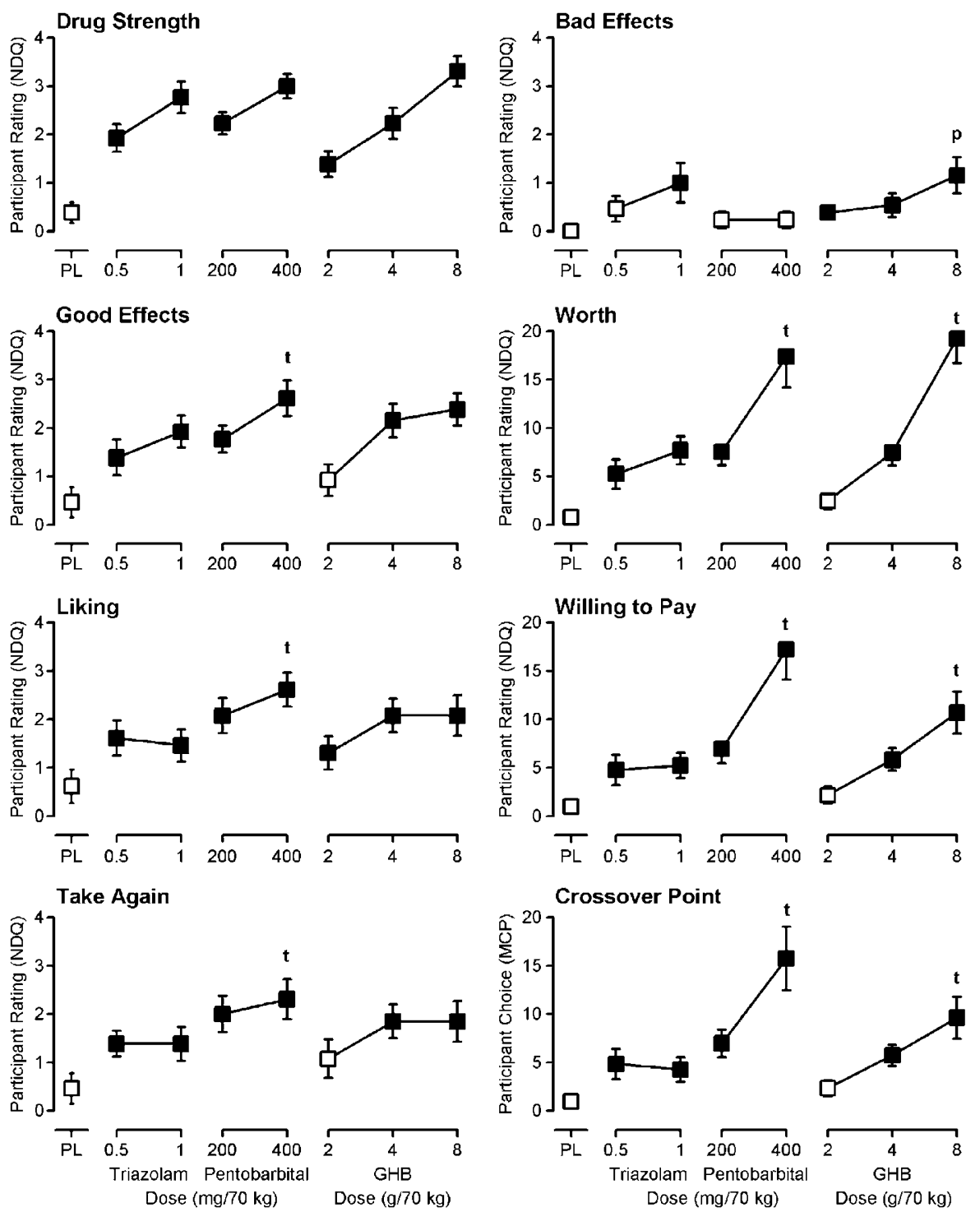

Figure 4 Next-day ratings of drug strength, bad effects, good effects, liking, and indirect and direct measures of reinforcement for triazolam, pentobarbital, and GHB. Y axes: next-day ratings (Next Day Questionnaire) and crossover point (Multiple Choice Procedure). $X$ axes: dose in mg (triazolam and pentobarbital) or $g(\mathrm{GHB})$ per $70 \mathrm{~kg}$ (log scale); PL designates placebo. Data points show means $(\mathrm{N}=13)$; brackets show \pm I SEM. See Figure 2 for other details.

participants' performance on the 0 or $10 \mathrm{~s}$ delayed recall component.

In a Word Recall task designed to test the participants' ability to remember words that they had seen $5 \mathrm{~h}$ earlier, doses of triazolam and pentobarbital decreased the mean $( \pm 1$ SEM) number of words that were recalled from $3.2 \pm 0.7$ after placebo to less than one word after any dose of triazolam or pentobarbital (Figure 5, fourth panel). The effects of $8 \mathrm{~g} / 70 \mathrm{~kg}$ GHB on the Word Recall (and Word Recognition) tasks were not analyzed because fewer than half of the participants were able to complete the word study part of the task $1 \mathrm{~h}$ after administration of $8 \mathrm{~g} / 70 \mathrm{~kg}$ GHB; however, $4 \mathrm{~g} / 70 \mathrm{~kg}$ GHB had less of an effect on Word Recall than $0.5 \mathrm{mg} / 70 \mathrm{~kg}$ triazolam or $200 \mathrm{mg} / 70 \mathrm{~kg}$ pentobarbital (Figure 5, fourth panel).

In the Word Recognition task, triazolam and pentobarbital significantly decreased the participants' ability to discriminate between new and old words (ie remember which words they had seen before), whereas GHB did not (Figure 5, bottom panel showing significantly lower d' values after administration of triazolam and pentobarbital compared to placebo or $4 \mathrm{~g} / 70 \mathrm{~kg} \mathrm{GHB})$. Unlike the Word Recall task, data from the Word Recognition task show that the highest dose of GHB that could be studied in these participants (ie they were awake to study the words $1 \mathrm{~h}$ after GHB administration) did not affect the participants' ability to discriminate new and old words.

\section{DISCUSSION}

One aim of this study was to assess the relative likelihood of abuse of GHB compared to triazolam and pentobarbital in human participants that use sedatives recreationally. In these participants, all next-day measures of reinforcing effects and positive drug effects of pentobarbital were 
greater than those of triazolam, which is consistent with previous human and non-human laboratory studies that have compared the reinforcing effects of these compounds (Griffiths et al, 1981, 1985; Roache and Griffiths, 1985). GHB
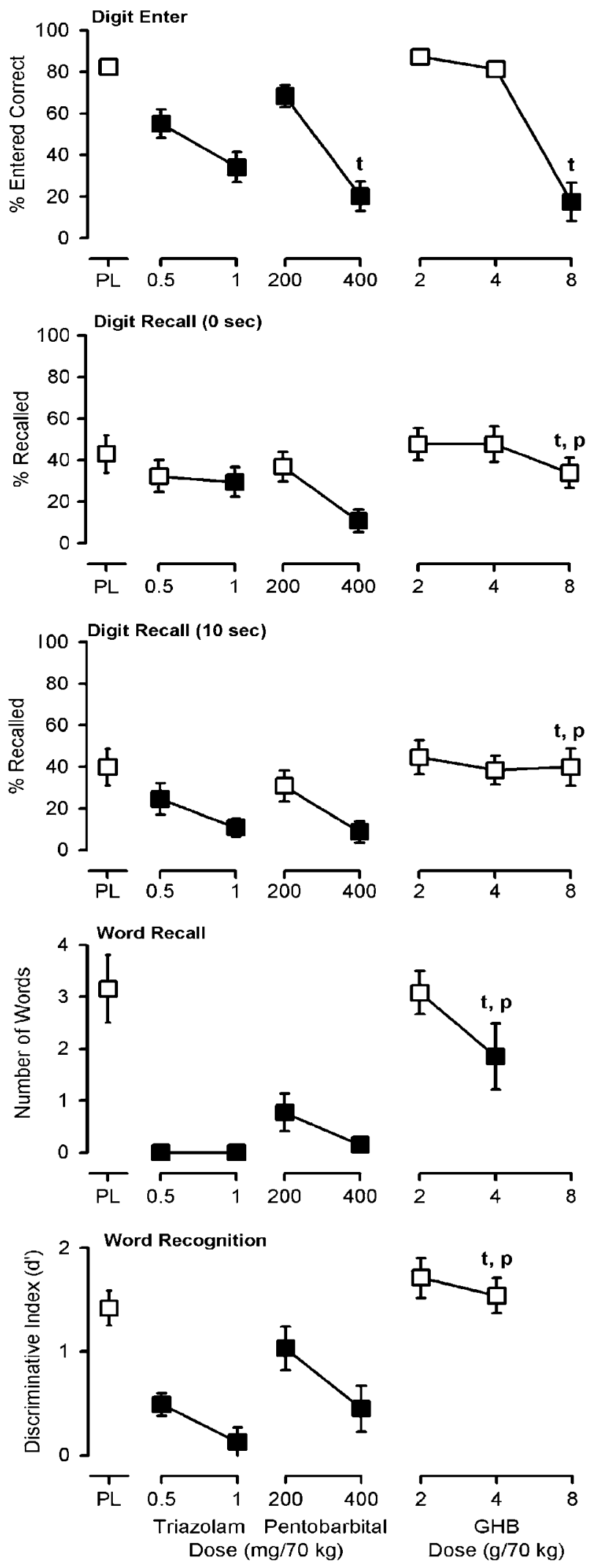

increased same-day and next-day measures of positive subjective effects and measures of drug reinforcement relative to placebo. Although GHB was tested at doses that produced substantially greater sedation than triazolam and pentobarbital (cf., Tables 1 and 2), the measures of positive subjective effects and of drug reinforcement after GHB were never statistically greater than pentobarbital - in fact, they were generally numerically smaller (five of six measures in Figure 4.), and sometimes statistically smaller than the high dose of pentobarbital (Table 3). In contrast, these effects of GHB were always numerically greater than the high dose of triazolam (six of six measures in Figure 4), and sometimes statistically greater (Table 2 ). In addition, GHB generally produced greater unpleasant drug effects (ie headache, sick to stomach, bad effects) than both triazolam or pentobarbital (cf., Figures 3 and 4; Tables 2 and 3). Overall, the relative likelihood of abuse of GHB is intermediate to that of triazolam and pentobarbital.

The time course of drug effects can influence the reinforcing effects and likelihood of abuse of drugs (Griffiths et al, 1985; Mumford et al, 1995). In the current study, high doses of pentobarbital and GHB tended to exhibit a faster onset of action (30 min) than triazolam (1 h), and the duration of action of pentobarbital was longer $(6-8 \mathrm{~h})$ than triazolam or GHB (2-4 h; cf., Figure 1). It is possible that the faster onset of action of pentobarbital and GHB compared to triazolam, or the longer duration of action of pentobarbital relative to triazolam and GHB (cf., Mintzer and Griffiths, 2005), might have contributed to greater participant ratings of direct and indirect measures of reinforcement (ie crossover point, worth, and willing to pay were significantly greater after pentobarbital and GHB than triazolam).

Consistent with the shared therapeutic indications of triazolam, pentobarbital, and GHB (induction of sleep and treatment of alcohol withdrawal), all three drugs decreased psychomotor performance and observer-rated level of alertness, increased observer ratings of muscle relaxation and abnormal posture, and increased participant ratings of sleepy, depressant or sedating, tired or lazy, and easy going or mellow. Triazolam, pentobarbital, and GHB did not increase participant ratings of arousing or stimulant, excited, restless, energetic, or shaky or jittery at any dose studied. Such a profile of effects for these drugs is consistent with previous findings with triazolam and pentobarbital (Mintzer et al, 1997; Rush et al, 1999) and extends previous findings with GHB (eg Rosen et al, 1997; Ferrara et al, 1999)

Figure 5 Cognitive performance measures for triazolam, pentobarbital, and GHB. Y axes: percentage of numbers entered or recalled (digit enter and recall), number of words recalled (Word Recall), and discriminative index ( $d^{\prime}$; Word Recognition). Data from the Digit Enter and Recall task are expressed as peak effects (minimum values across the $12 \mathrm{~h}$ session); the Word Recognition and Recall task was performed once per session. $X$ axes: dose in $\mathrm{mg}$ (triazolam and pentobarbital) or g (GHB) per $70 \mathrm{~kg}$ (log scale); $\mathrm{PL}$ designates placebo. Data points show means $(N=13)$; brackets show \pm I SEM. Data for $8 \mathrm{~g} / 70 \mathrm{~kg}$ GHB are not shown for the Word Recognition and Word Recall tasks because less than half of the participants completed the word study task I h after administration. Letters above 4 g/70 kg GHB for the Word Recall and Word Recognition tasks indicate that these values are significantly different from I mg/70 kg triazolam and $400 \mathrm{mg} / 70 \mathrm{~kg}$ pentobarbital; $p<0.05$; planned comparisons. See Figure 2 for other details. 
by characterizing large, supratherapeutic doses of GHB across a broad range of measures.

Although there were substantial similarities in subjective effects of the three drugs, GHB produced greater unpleasant effects than either pentobarbital or triazolam. Consistent with reports of GHB use outside of the laboratory setting (eg Miotto et al, 2001; Degenhardt et al, 2002), GHB significantly increased same-day participant-ratings of headache and queasy or sick to stomach and next-day ratings of bad effects. Nausea, GI distress, diarrhea, or vomiting occurred during 41 and $78 \%$ of the sessions in which doses of 2-8 and $10-18 \mathrm{~g} / 70 \mathrm{~kg}$ GHB were administered, respectively, which is consistent with the high frequency of adverse GI effects of GHB described in other clinical reports of GHB toxicity (eg Degenhardt et al, 2002; Couper et al, 2004; Liechti et al, 2006). Unlike GHB, reports of nausea, GI distress, diarrhea, or vomiting after doses of triazolam or pentobarbital occurred after only 4 and $14 \%$ of sessions, respectively. In open-ended written comments on the Next Day Questionnaire, participants that reported disliking GHB cited effects such as nausea, GI distress, and loss of consciousness as reasons for disliking the drug. Thus, it is possible that the unpleasant effects of GHB might limit the liability of GHB for abuse by people who are sensitive to these adverse effects.

Despite an overlapping profile of subjective effects among triazolam, pentobarbital, and GHB, GHB was rarely identified as a benzodiazepine or barbiturate and identification of GHB as either a barbiturate or a benzodiazepine was not dose-related. This finding is consistent with GHB occasioning little or no drug-appropriate responding in rhesus monkeys trained to discriminate triazolam or pentobarbital (Woolverton et al, 1999), and with triazolam and pentobarbital (positive $\mathrm{GABA}_{\mathrm{A}}$ receptor modulators) having different pharmacological mechanisms of action than $\mathrm{GHB}$, which is a $\mathrm{GABA}_{\mathrm{B}}$ receptor agonist (Mathivet et al, 1997) and specific GHB receptor ligand (Benavides et al, 1982). Given that the prototypical $\mathrm{GABA}_{\mathrm{B}}$ receptor agonist baclofen (Lioresal) is used therapeutically as a muscle relaxant, it is somewhat surprising that GHB was not identified as a muscle relaxant more often (two participants identified a dose of GHB as a muscle relaxant; one after $2 \mathrm{~g} /$ $70 \mathrm{~kg}$ and one after $4 \mathrm{~g} / 70 \mathrm{~kg} \mathrm{GHB}$ ), although this result might be due to participants' lack of experience with this class of compounds (muscle relaxants).

Given that the design of this study included evaluating doses of GHB up to those that produced behavioral impairment and greater observer-rated sedation than triazolam and pentobarbital, it might be expected that the peak subjective effects of GHB would be greater than those of triazolam or pentobarbital. However, the same-day peak subjective effects of $400 \mathrm{mg} / 70 \mathrm{~kg}$ pentobarbital were generally greater than those of the $8 \mathrm{~g} / 70 \mathrm{~kg}$ GHB dose and the highest dose of GHB that was received (cf., Table 3, two rightmost columns), indicating that when participants were able to respond, they rated the effects of GHB lower than the highest dose of pentobarbital. A major factor contributing to this dissociation between observer-rated sedation and peak magnitude of subjective effect is that there were more occasions of nonresponding at time of peak effects after high doses of GHB than after triazolam or pentobarbital (Table 3). The finding that the magnitude of peak subjective effects of $400 \mathrm{mg} / 70 \mathrm{~kg}$ pentobarbital was also generally greater than that of $1 \mathrm{mg} / 70 \mathrm{~kg}$ triazolam at doses that produced equivalent deficits in psychomotor performance and observer-rated measures of sedation is consistent with a previous finding that participants tend to underestimate the effects of triazolam relative to pentobarbital (Roache and Griffiths, 1985).

Given that many clinical reports describing GHB abuse and 'date-rape' claim that GHB produces robust anterograde amnesia (eg Schwartz et al, 2000; Varela et al, 2004), it is interesting that the effects of GHB on memory processes in this study were significantly less than those of triazolam and pentobarbital. Specifically, the findings presented in Figure 5 indicate that GHB, unlike triazolam and pentobarbital, did not impair participants' recall of eight-digit numbers when they were able to replicate (enter) those numbers. Further, at doses in which participants were able to study a list of words, GHB did not impair the participants' ability to discriminate new and old words $5 \mathrm{~h}$ later. Taken together, these data show that up to doses that prevented the assessment of cognitive effects (eg loss of consciousness) the effects of GHB on these memory tasks were significantly less than those of triazolam and pentobarbital and not significantly different from placebo. The finding that the impairment of participants' free recall of words after $4 \mathrm{~g} / 70 \mathrm{~kg}$ GHB was significantly greater than after placebo, but significantly less than after triazolam or pentobarbital, is consistent with previous reports that have shown that the impairment of memory processes by GHB, when observed (eg Grove-White and Kelman, 1971) was less than the impairment produced by benzodiazepines and barbiturates (diazepam, methohexitone, and quinalbarbitone; Metcalf et al, 1966; Grove-White and Kelman, 1971). Thus, it is possible that the 'amnesia' that is often attributed to GHB in clinical reports is due to loss of consciousness and not any selective impairment of memory processes. Further characterization of the effects of GHB across procedures that are designed to test different aspects of memory might help determine whether GHB affects specific memory processes.

GHB intoxication and overdose have been well documented in case reports (Freese et al, 2002; Bosman and Lusthof, 2003; Degenhardt et al, 2003; Liechti et al, 2006). One explanation for the apparently high frequency of accidental GHB overdose (ie a greater level of sedation than intended, sometimes resulting in medical intervention), even among experienced users (Miotto et al, 2001; Degenhardt et al, 2002, 2003), is the variability of volume, concentration, and identity of GHB solutions on the street (eg GHB precursors or analogs are sold as substitutes for GHB; Zvosec et al, 2001), which makes it difficult to estimate a desired dose for self-administration (Degenhardt et al, 2003). In this study, known doses of GHB were administered on a weight-adjusted basis and under controlled conditions, thereby eliminating the aforementioned sources of variability and the possibility of cointoxicants. The data show that even under these conditions, substantial differences in sensitivity to GHB can exist, at least in recreational sedative users. That GHB produced qualitatively similar subjective effects as classic sedatives, but to a lesser magnitude, might account for some cases of unintended GHB overdose in experienced sedative 
users who consume large amounts of GHB, or consume GHB with other intoxicants (Miotto et al, 2001; Degenhardt et $a l, 2003$; Liechti et al, 2006), in pursuit of an expected level of subjective effects.

It is noteworthy that there were no serious adverse events given that most participants received a dose of $\mathrm{GHB}$ that produced a level of sedation requiring tactile or nociceptive stimuli for arousal. Even when highly sedated, respiration and blood pressure were well maintained with a slight decrease in heart rate. Participants generally recovered from strong GHB drug effects feeling alert and well rested, although a minority of participants reported a persisting headache.

The overall abuse liability of a drug refers to both its likelihood of abuse and its potential for producing adverse consequences as a result of its abuse (eg toxicity; Griffiths et al, 1985; Griffiths and Johnson, 2005). On most measures of likelihood of abuse (eg ratings of liking, reinforcing effects), effects of pentobarbital were significantly greater than those of triazolam, with GHB being intermediate up to doses of GHB that produced marked sedation and behavioral impairment. Characteristics of GHB that contribute to a greater potential for adverse effects include the between-subject variability in sensitivity, the steep dose-effect function for behavioral effects, and the profound sedation (ie sedation requiring nociceptive stimuli for arousal) observed after higher doses. Taken together, these data suggest that the likelihood for GHB to be abused is intermediate to triazolam and pentobarbital, although the risk of accidental overdose (ie inducing a greater level of sedation than intended) with GHB might be greater.

\section{ACKNOWLEDGEMENTS}

We would like to thank Kristina Burns, Linda Felch, Paul Nuzzo, and John Yingling for excellent technical assistance. We also thank Matthew Johnson for helpful discussion and editorial comments. This research was supported by the National Institute on Drug Abuse Grant R01 DA003889 (RRG) and an unrestricted grant from Orphan Medical Inc. (now known as Jazz Pharmaceuticals). GHB and GHB placebo solutions were generously provided by Orphan Medical; Minnetonka, MN, now known as Jazz Pharmaceuticals, Palo Alto, CA.

\section{REFERENCES}

Addolorato G, Castelli E, Stefanini GF, Casella G, Caputo F, Marsigli L et al (1996). An open multicentric study evaluating 4hydroxybutyric acid sodium salt in the medium-term treatment of 179 alcohol dependent subjects. GHB Study Group. Alcohol Alcohol 31: 341-345.

Barrett SP, Gross SR, Garand I, Pihl RO (2005). Patterns of simultaneous polysubstance use in Canadian rave attendees. Subst Use Misuse 40: 1525-1537.

Beardsley PM, Balster RL, Harris LS (1996). Evaluation of the discriminative stimulus and reinforcing effects of gammahydroxybutyrate (GHB). Psychopharmacology 127: 315-322.

Beghè F, Carpanini MT (2000). Safey and tolerability of gammahydroxybutyrc acid in the treatment of alcohol-dependent patients. Alcohol 20: 223-225.
Bellis MA, Hughes K, Bennett A, Thomson R (2003). The role of an international nightlife resort in the proliferation of recreational drugs. Addiction 98: 1713-1721.

Benavides J, Rumigny JF, Bourguignon JJ, Cash C, Wermuth CG, Mandel $P$ et al (1982). High affinity binding sites for gammahydroxybutyric acid in rat brain. Life Sci 30: 953-961.

Borgen LA, Okerholm RA, Lai A, Scharf MB (2004). The pharmacokinetics of sodium oxybate oral solution following acute and chronic administration to narcoleptic patients. J Clin Pharmacol 44: 253-257.

Bosman IJ, Lusthof KJ (2003). Forensic cases involving the use of GHB in The Netherlands. Forensic Sci Int 133: 17-21.

Caldicott DG, Chow FY, Burns BJ, Felgate PD, Byard RW (2004). Fatalities associated with the use of gamma-hydroxybutyrate and its analogues in Australasia. Med J Aust 181: 310-313.

Colombo G, Agabio R, Balaklievskaia N, Diaz G, Lobina C, Reali R et al (1995). Oral self-administration of gamma-hydroxybutyric acid in the rat. Eur J Pharmacol 285: 103-107.

Colombo G, Agabio R, Diaz G, Fa M, Lobina C, Reali R et al (1998). Gamma-hydroxybutyric acid intake in ethanol-preferring sP and nonpreferring sNP rats. Physiol Behav 64: 197-202.

Couper FJ, Thatcher JE, Logan BK (2004). Suspected GHB overdoses in the emergency department. J Anal Toxicol 28: 481-484.

Degenhardt L, Copeland J, Dillon P (2005). Recent trends in the use of 'club drugs': an Australian review. Subst Use Misuse 40: $1241-1256$.

Degenhardt L, Darke S, Dillon P (2002). GHB use among Australians: characteristics, use patterns and associated harm. Drug Alcohol Depend 67: 89-94.

Degenhardt L, Darke S, Dillon P (2003). The prevalence and correlates of gamma-hydroxybutyrate (GHB) overdose among Australian users. Addiction 98: 199-204.

Fattore L, Cossu G, Martellotta C, Deiana S, Fratta W (2001). Baclofen antagonises intravenous self-administration of $\gamma$-hydroxybutyric acid in mice. Neuroreport 12: 2243-2246.

Ferrara SD, Giorgetti R, Zancaner S, Orlando R, Tagliabracci A, Cavarzeran $\mathrm{F}$ et al (1999). Effects of single dose gammahydroxybutyric acid and lorazepam on psychomotor performance and subjective feelings in healthy volunteers. Eur J Clin Pharmacol 54: 821-827.

Freese TE, Miotto K, Reback CJ (2002). The effects and consequences of selected club drugs. J Subst Abuse Treat 23: 151-156.

Fuller DE, Hornfeldt CS (2003). From club drug to orphan drug: sodium oxybate (Xyrem) for the treatment of cataplexy. Pharmacotherapy 23: 1205-1209.

Galloway GP, Frederick SL, Staggers FE, Gonzales M, Stalcup SA, Smith DE (1997). Gamma-hydroxybutyrate: an emerging drug of abuse that causes physical dependence. Addiction 92: 89-96.

Gonzalez A, Nutt DJ (2005). Gamma hydroxy butyrate abuse and dependency. J Psychopharmacol 19: 195-204.

Griffiths RR, Bigelow GE, Ator NA (2003). Principles of initial experimental drug abuse liability assessment in humans. Drug Alcohol Depend 70: S41-S54.

Griffiths RR, Bigelow GE, Liebson I (1983). Differential effects of diazepam and pentobarbital on mood and behavior. Arch Gen Psychiatry 40: 865-873.

Griffiths RR, Bigelow GE, Liebson I, Kaliszak JE (1980). Drug preference in humans: double-blind choice comparison of pentobarbital, diazepam and placebo. J Pharmacol Exp Ther 215: 649-661.

Griffiths RR, Johnson MW (2005). Relative abuse liability of hypnotic drugs: a conceptual framework and algorithm for differentiating among compounds. J Clin Psychiatry 9: 31-41.

Griffiths RR, Lamb RJ, Ator NA, Roache JD, Brady JV (1985). Relative abuse liability of triazolam: experimental assessment in animals and humans. Neurosci Biobehav Rev 9: 133-151. 
Griffiths RR, Lukas SE, Bradford LD, Brady JV, Snell JD (1981). Self-injection of barbiturates and benzodiazepines in baboons. Psychopharmacology 75: 101-109.

Griffiths RR, Troisi JR, Silverman K, Mumford GK (1993). Multiple-choice procedure: an efficient approach for investigating drug reinforcement in humans. Behav Pharmacol 4: 3-13.

Grove-White IG, Kelman GR (1971). Effect of methohexitone, diazepam and sodium 4-hydroxybutyrate on short-term memory. Br J Anaesth 43: 113-116.

Itzhak Y, Ali SF (2002). Repeated administration of gammahydroxybutyric acid (GHB) to mice: assessment of the sedative and rewarding effects of GHB. Ann NY Acad Sci 965: 451-460.

Kintz P, Villain M, Pélissier A, Cirimele V, Leonetti G (2005). Unusually high concentrations in a fatal GHB case. J Anal Toxicol 29: 582-585.

Liechti ME, Kunz I, Greminger P, Speich R, Kupferschmidt $\mathrm{H}$ (2006). Clinical features of gamma-hydroxybutyrate and gammabutyrolactone toxicity and concomitant drug and alcohol use. Drug Alcohol Depend 81: 323-326.

Maitre M (1997). The ã-hydroxybutyrate signaling system in brain: organization and functional implications. Prog Neurobiol 51: 337-361.

Martellotta MC, Cossu G, Fattore L, Gessa GL, Fratta W (1998). Intravenous self-administration of gamma-hydroxybutyric acid in drug-naïve mice. Eur Neuropsychopharmacology 8: 293-296.

Martellotta MC, Fattore L, Cossu G, Fratta W (1997). Rewarding properties of gamma-hydroxybutyric acid: an evaluation through place preference paradigm. Psychopharmacology 132: $1-5$.

Mathivet P, Bernasconi R, De Barry J, Marescaux C, Bittiger H (1997). Binding characteristics of $\gamma$-hydroxybutyric acid as a weak but selective $\mathrm{GABA}_{\mathrm{B}}$ receptor agonist. Eur J Pharmacol 321: 67-75.

McLeod D, Griffiths RR, Bigelow GE, Yingling J (1982). An automated version of the digit symbol substitution test (DSST). Behav Res Methods Instrum 14: 463-466.

Metcalf DR, Emde RN, Stripe JT (1966). An EEG-behavioral study of sodium hydroxybutyrate in humans. Electroenceph Clin Neurophysiol 20: 506-512.

Mintzer MZ, Griffiths RR (1998). Flunitrazepam and triazolam: a comparison of behavioral effects and abuse liability. Drug Alcohol Depend 53: 49-66.

Mintzer MZ, Griffiths RR (2005). An abuse liability comparison of flunitrazepam and triazolam in sedative drug abusers. Behav Pharmacol 16: 579-584.

Mintzer MZ, Guarino J, Kirk T, Roache JD, Griffiths RR (1997). Ethanol and pentobarbital: comparison of behavioral and subjective effects in sedative drug abusers. Exp Clin Psychopharmacol 5: 203-215.

Miotto K, Darakjian J, Basch J, Murray S, Zogg J, Rawson R (2001). Gamma-hydroxybutyric acid: patterns of use, effects and withdrawal. Am J Addict 10: 232-241.

Mumford GK, Rush CR, Griffiths RR (1995). Abecarnil and alprazolam in humans: behavioral, subjective and reinforcing effects. J Pharmacol Exp Ther 272: 570-580.

Nicholson KL, Balster RL (2001). GHB: a new and novel drug of abuse. Drug Alcohol Depend 63: 1-22.

Poldrugo F, Addolorato G (1999). The role of $\gamma$-hydroxybutyric acid in the treatment of alcoholism: from animal to clinical studies. Alcohol Alcohol 34: 15-24.

Roache JD, Griffiths RR (1985). Comparison of triazolam and pentobarbital: performance impairment, subjective effects and abuse liability. J Pharmacol Exp Ther 234: 120-133.

Roache JD, Griffiths RR (1987). Lorazepam and meprobamate dose effects in humans: behavioral effects and abuse liability. J Pharmacol Exp Ther 243: 978-988.

Romanelli F, Smith KM, Pomeroy C (2003). Use of club drugs by HIV-seropositive and HIV-seronegative gay and bisexual men. Top HIV Med 11: 25-32.

Rosen MI, Pearsall HR, Woods SW, Kosten TR (1997). Effects of gamma-hydroxybutyric acid (GHB) in opioid-dependent patients. J Subst Abuse Treat 14: 149-154.

Rush CR, Frey JM, Griffiths RR (1999). Zaleplon and triazolam in humans: acute behavioral effects and abuse potential. Psychopharmacology 145: 39-51.

Schwartz RH, Milteer R, LeBeau MA (2000). Drug facilitated sexual assault ('date rape'). South Med J 93: 558-561.

Snodgrass JG, Corwin J (1988). Pragmatics of measuring recognition memory: applications to dementia and amnesia. $J$ Exp Psychcol Gen 117: 34-50.

Varela M, Nogue S, Oros M, Miro O (2004). Gamma hydroxybutyrate use for sexual assault. Emerg Med J 21: 255-256.

Wechsler D (1958). The Measurement and Appraisal of Adult Intelligence. Williams \& Wilkins: Baltimore, MD.

Woolverton WL, Rowlett JK, Winger G, Woods JH, Gerak LR, France CP (1999). Evaluation of the reinforcing and discriminative stimulus effects of $\gamma$-hydroxybutyrate in rhesus monkeys. Drug Alcohol Depend 54: 137-143.

Zawertailo LA, Busto UE, Kaplan HL, Greenblatt DJ, Sellers EM (2003). Comparative abuse liability and pharmacological effects of meprobamate, triazolam, and butabarbital. J Clin Psychopharmacol 23: 269-280.

Zvosec DL, Smith SW, McCutcheon JR, Spillane J, Hall BJ, Peacock EA (2001). Adverse events, including death, associated with the use of 1,4-butanediol. $N$ Engl J Med 344: 87-94. 